\title{
Monetary Policy and Bond Option Pricing in an Analytical RBC Model
}

\author{
Paul Söderlind* \\ Stockholm School of Economics
}

3 January 2003

\begin{abstract}
This paper analyzes how bond option prices are affected by different types of monetary policy. Analytical results from a general equilibrium model with sticky wages show that employment or output targeting typically give lower bond option prices than inflation targeting.
\end{abstract}

Keywords: inflation targeting, output targeting, interest rates.

JEL Classification Numbers: E52, E44, G12.

* Stockholm School of Economics and CEPR. Address: Stockholm School of Economics, PO Box 6501, SE11383 Stockholm, Sweden. E-mail: Paul.Soderlind@hhs.se. I thank an anonymous referee for very helpful comments. 


\section{Introduction}

This paper studies how different monetary policy objectives (inflation targeting or employment/output targeting) affect the pricing of bond options. My approach is to derive optimal monetary policy rules in the business cycle model with sticky nominal wages of Bénassy (1995) and to study the implications for uncertainty about future bond prices. I try to keep the analysis simple and to arrive at closed-form solutions.

The main result of the paper is that employment or output targeting typically gives lower bond option prices than inflation targeting.

The paper is organized as follows: Section 2 summarizes the macro model, Section 3 derives optimal monetary policy for different policy objectives, Section 4 compares bond option prices in different policy regimes, and Section 5 discusses the model and the results.

\section{Bénassy's Model}

The model in Bénassy (1995) is based on the real business cycle model in Long and Plosser (1983), but has money in the utility function and sticky nominal wages.

The Cobb-Douglas production function depends on total factor productivity, $Z_{t}$, capital stock, $K_{t}$, and labour input, $H_{t}$,

$$
Y_{t}=Z_{t} K_{t}^{\alpha} H_{t}^{1-\alpha} \text { with } 0<\alpha<1 .
$$

Competitive firms rent labour and capital from households. To get a closed form solution, capital accumulation is approximated as in Hercowitz and Sampson (1991)

$$
K_{t+1}=A K_{t}^{1-\delta} I_{t}^{\delta}
$$

where $I_{t}$ is investment. The value $\delta=1$ can be thought of as complete depreciation (the model in Long and Plosser (1983)).

Households choose consumption, $C_{t}$, money holdings, $M_{t}$, and labour supply, $H_{t}$, to maximize expected discounted utility

$$
\mathrm{E}_{0} \sum_{t=0}^{\infty} \beta^{t}\left[\ln C_{t}+\theta \ln M_{t} / P_{t}+V\left(1-H_{t}\right)\right], \theta>0
$$

where $V$ is a concave function and labour endowment is normalized to unity. The budget 
restriction

$$
C_{t}+M_{t} / P_{t}+I_{t}=H_{t} W_{t} / P_{t}+R_{t}\left(I_{t-1}+q_{t-1} K_{t-1}\right)+\mu_{t} M_{t-1} / P_{t}
$$

says that the sum of consumption, and the real values of the money holdings and investments in period $t$ equals the sum of real wage earnings ( $W_{t}$ is the nominal wage rate), rental income from capital, and the real value of cash brought over from the previous period. The capital income is the real return on capital $\left(R_{t}\right)$ times the real value of capital owned by the household $\left(I_{t-1}+q_{t-1} K_{t-1}\right.$, where $q_{t}$ is the real price of installed capital). Cash brought over from $t-1$ includes a "seigniorage dividend" $\left(\mu_{t} \neq 1\right)$ so money should be thought of as a kind of deposits rather than cash. ${ }^{1}$ The aggregate resource constraint is that output equals consumption plus investment (a closed economy).

Nominal wage contracts are written one period in advance: the log nominal wage is set equal to the expected log nominal marginal product of labour-and households are obliged to supply any labour demand at the realized real wage. An expansionary monetary policy surprise can therefore increase output by creating a surprise inflation (low real wage rate).

Bénassy (1995) shows that, in equilibrium, consumption and capital accumulation are proportional to output, the velocity equation holds, and employment is proportional to the money supply surprise.

Let lowercase letters denote logs and assume that log productivity is a stationary AR(1)

$$
z_{t}=\rho z_{t-1}+\varepsilon_{t} \text {, where } \varepsilon_{t} \text { is iid } N\left(0, \sigma^{2}\right) \text { and }|\rho|<1 \text {. }
$$

The key equations for the dynamic equilibrium are then (except for constants)

$$
\begin{aligned}
p_{t} & =m_{t}-y_{t}, \\
h_{t} & =m_{t}-\mathrm{E}_{t-1} m_{t}, \text { and } \\
y_{t} & =(\rho+\delta-1) z_{t-1}+(1-\delta+\delta \alpha) y_{t-1}-(1-\alpha)(1-\delta) h_{t-1}+(1-\alpha) h_{t}+\varepsilon_{t} .
\end{aligned}
$$

Equation (6) is the log of the velocity equation, (7) states that log employment equals the (log) money supply surprise, and (8) is the production function where we have used the capital accumulation equation (2) and the result that investment is proportional to output.

\footnotetext{
${ }^{1}$ This simplifies the solution to a large extent, and is probably not important as other authors (for instance, Cooley and Hansen (1995)) have found that the distortion caused by the zero interest rate on cash has a very small effect on business cycle movements.
} 
Apart from monetary policy, there are only three parameters in the model: the elasticity of next-period capital with respect to current investment, $\delta$, the capital share of output, $\alpha$, and the autocorrelation of productivity, $\rho$.

The length of the time periods is best thought of as the length of nominal wage contracts, so something between a quarter and a year makes sense.

\section{Optimal Monetary Policy}

The central bank chooses a policy rule for log money supply with the objective of stabilizing log employment and inflation. The objective function is

$$
\lambda \operatorname{Var}\left(h_{t}\right)+(1-\lambda) \operatorname{Var}\left(\pi_{t}\right)
$$

where $\pi_{t}=p_{t}-p_{t-1}$ is the inflation rate. There is no particular micro foundation for this objective function, but it is widely used in analysis of monetary policy.

The optimization problem is easy once we realize that expected and unexpected money supply have very different effects. Decompose the inflation variance in (9) as $\operatorname{Var}\left(\pi_{t}\right)=$ $\operatorname{Var}\left(\mathrm{E}_{t-1} \pi_{t}\right)+\operatorname{Var}\left(\pi_{t}-\mathrm{E}_{t-1} \pi_{t}\right)$, that is, as the sum of the variances of expected and unexpected inflation. Expected money supply, $\mathrm{E}_{t-1} m_{t}$, cannot affect employment (see (7)) or unexpected inflation (by definition). This means that the predictable part of the policy rule can be used for making expected inflation zero in every period, $\operatorname{Var}\left(\mathrm{E}_{t-1} \pi_{t}\right)=0$.

Now, consider the unpredictable part of the policy rule. The model is linear-quadratic and the only reason to generate money supply surprises is that they can counteract productivity shocks. The unpredictable part of the policy rule is therefore linear in the productivity shock. Together these considerations (and some algebra in Appendix) give the optimal policy rule

$$
\begin{aligned}
m_{t} & =m_{t-1}+(\rho+\delta-1) z_{t-1}+\delta(\alpha-1) y_{t-1}-(1-\alpha)(1-\delta) h_{t-1}+v \varepsilon_{t}, \\
v & =[(1-\lambda) \alpha] /\left[\alpha^{2}+\lambda\left(1-\alpha^{2}\right)\right] .
\end{aligned}
$$

The first four terms in (10) make expected inflation zero. The last term is a feedback from the productivity shock (and therefore unpredictable) which trades off variance in employment against variance in inflation surprises. The $v$ coefficient is monotonically decreasing in the weight on employment, $\lambda$.

When the central bank cares about inflation only $(\lambda=0)$, then $v=1 / \alpha$, which is positive. 
The intuition is that a positive productivity shock increases output and therefore money demand. By increasing money supply $(v>0)$, the central bank can restore equilibrium on the money market (6) at an unchanged price level.

When the central bank cares about employment only $(\lambda=1)$, then $v=0$. The reason is that unpredictable money supply hits employment directly (see (7)), so movements in employment can be avoided by giving wage setters full information about next period's monetary policy.

We now change the loss function a bit by letting the central bank care about output instead of employment. The policy rule has the same form as (10), except that the $v$ coefficient is more complicated (see Appendix). The optimal $v$, which is negative, now takes into account that unpredictable money supply affects not only current output, but (unlike employment) also future output due to capital accumulation.

As an example, when capital depreciates completely $(\delta=1$, the model in Long and Plosser (1983)), then output targeting only gives $v=-1 /[(1-\alpha)(1-\alpha \rho)]$, which is negative. The intuition is that a positive productivity shock is met by a contractionary monetary policy, which increases the real wage and reduces labour demand. In the simplest case without autocorrelation in productivity, $\rho=0$, this offsets the productivity shock completely. With positive autocorrelation, $\rho>0$, money supply is decreased further in order to drive down investments. In this way, today's monetary policy can partially counterbalance the continued high productivity in future periods. We get a similar, but weaker, effect with partial depreciation $(\delta<1)$. The effect is weaker since it is harder to make a big impact on future capital stock by adjusting today's investment.

\section{Bond Option Pricing}

The equilibrium of the model in Section 2 is not affected by adding financial instruments (in zero net supply) to the investment opportunity set. We can therefore price such instruments by the standard Euler equation approach.

Let $B_{t+1}$ be the nominal price (in $t+1$ ) of a nominal one-period bond. The gross real return in $t+2$ is $P_{t+1} /\left(P_{t+2} B_{t+1}\right)$, so the Euler equation is

$$
B_{t+1}=\mathrm{E}_{t+1} \beta \frac{C_{t+1}}{C_{t+2}} \frac{P_{t+1}}{P_{t+2}} .
$$

The stochastic discount factor, $\beta C_{t+1} / C_{t+2}$, follows from the logarithmic utility function.

Equations (6)-(8) and the linear policy rule imply that the log of the nominal consumption 
expenditure, $C_{t+2} P_{t+2}$, is a linear function of the normally distributed productivity shockand that the innovation is $v \varepsilon_{t+2}$. It follows that the conditional distribution in (12) is jointly lognormal and the log bond price in $t+1$ is

$$
b_{t+1}=\ln \beta-\mathrm{E}_{t+1}\left(c_{t+2}-c_{t+1}\right)-\mathrm{E}_{t+1} \pi_{t+2}+v^{2} \sigma^{2} / 2 .
$$

This is essentially the Fisher equation (with a minus sign). The first two terms capture the real interest rate ${ }^{2}$ and the third term is the compensation for expected inflation.

A call option on a one-period bond is priced in a similar way. Let $G_{t}$ be the nominal price of a call option with nominal strike price $X$ and expiration date $t+1$. The gross real return in $t+1$ is $\max \left(0, B_{t+1}-X\right) P_{t} /\left(P_{t+1} G_{t}\right)$, so the Euler equation for the option is

$$
G_{t}=\mathrm{E}_{t} \beta \frac{C_{t}}{C_{t+1}} \frac{P_{t}}{P_{t+1}} \max \left(0, B_{t+1}-X\right) .
$$

The normal distribution of log consumption and log prices carry over to their expected values (because of linearity). This means that the distribution of $C_{t+1} P_{t+1}$ and $B_{t+1}$, conditional on the information set in $t$, is jointly lognormal. The solution to (14) is therefore the Black-Scholes formula, although for discrete time (see, for instance, Huang and Litzenberger (1988)).

The key factor in the Black-Scholes formula is the volatility of the asset, here the conditional variance of the future $\log$ bond price $b_{t+1}$ (the future one-period nominal interest rate). ${ }^{3}$ The rest of the analysis focuses on this volatility, which is (use (6) and (10) in (13))

$$
\operatorname{Var}_{t}\left(b_{t+1}\right)=[1-\rho-\alpha \delta+(1-\alpha)(1-\alpha \delta) \nu]^{2} \sigma^{2}
$$

Different monetary policies give different values of $v$ and therefore affect the volatility. I focus on the extreme policy cases which (according to Section 3 ) have qualitatively different implications for $v$ : inflation targeting only $(v>0)$, employment targeting only $(v=0)$, and output targeting only $(v<0){ }^{4}$

Figure 1.a shows that the volatility of employment targeting is typically lower than the volatility of inflation targeting unless both the capital share of output $(\alpha)$ and the autocorrela-

\footnotetext{
${ }^{2}$ To be more precise, the $\log$ price of a real one-period bond in $t+1$ is $\ln \beta-\mathrm{E}_{t+1}\left(c_{t+2}-c_{t+1}\right)+[1+(1-$ $\alpha) \nu]^{2} \sigma^{2} / 2$.

${ }^{3}$ The other factors are the current one-period interest rate and the spot price of the underlying asset which here is a two-period nominal zero-coupon bond.

${ }^{4}$ Strictly speaking the predictable part of the policy rule is indeterminate if inflation has zero weight. However, with a trivial (but positive) weight on inflation the predictable part is as in (10), but $v$ is almost identical to that with employment/output targeting only.
} 
Lower vol with

a. Regions vol: $h$ vs $\pi$ target inflation target

b. Regions vol: $y$ vs $\pi$ target

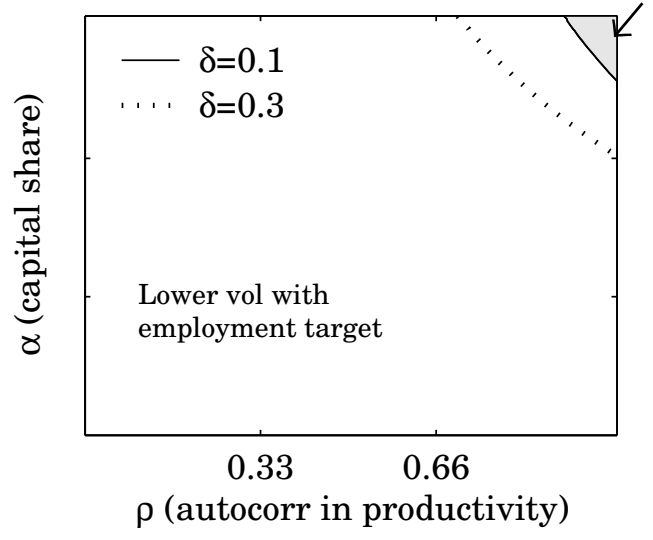

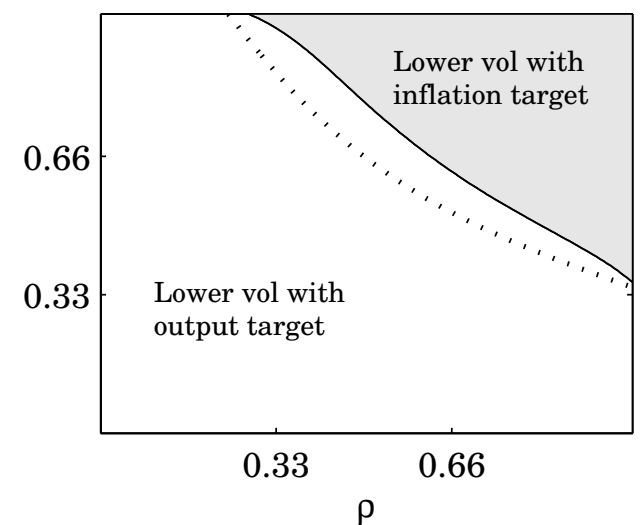

Figure 1: Parameter regions for lower bond price volatility (vol). The parameter regions ( $\rho$ and $\alpha$ ) where employment targeting or output targeting gives lower conditional volatility of the log bond price than inflation targeting. The $\delta$ parameter (the elasticty of $K_{t+1}$ with respect to $I_{t}$ ) is set to 0.1 or 0.3 .

tion of productivity $(\rho)$ are both very high. This particular figure is based on values of $\delta$ (the elasticity of next period's capital stock with respect to current investment) equal to 0.1 or 0.3 : the curve shifts to the northeast if $\delta$ is decreased. Figure $1 . b$ makes the same kind of comparison of output targeting and inflation targeting — and we find the same pattern, except that it now takes less extreme values of $\alpha$ and $\rho$ to get a lower volatility under inflation targeting.

The southeast regions (high $\rho$, low $\alpha$ ) of these figures are probably the most relevant. The autocorrelation of quarterly productivity is typically estimated to be 0.9 or higher and the capital share of GDP no larger than 0.4 (see Cooley and Prescott (1995) for a summary of efforts to calibrate macro models). These figures are drawn using $\delta=0.1$ and 0.3 , where $\delta$ is the elasticity of next period's capital stock with respect to current investment. This parameter should probably be low, probably no higher than 0.1 . The reason is that quarterly investment is small compared to the capital stock. ${ }^{5}$

The main result is thus that employment or output targeting typically gives lower implied

\footnotetext{
${ }^{5}$ Similarly, a first-order Taylor approximation of a standard accumulation equation $K_{t+1}=(1-d) K_{t}+I_{t}$ around the steady state values gives the $\log$ values $k_{t+1} \approx(1-d) k_{t}+d i_{t}$ plus a constant. The parameter $\delta$ is therefore approximately the same as $d$-and quarterly depreciation, $d$, is often estimated to be no larger than 0.02 . We can also note that Hercowitz and Sampson (1991) report very imprecise estimates of $\delta$, but get a value of 0.34 for their annual GNP\&hours data set, which could be translated into 0.08 for a quarterly period length; Collard (1999) argues for a quarterly value of $\delta=0.02$, and Cassou and Lansing (1998) for an annual value of $0.1(0.025$ per quarter).
} 
volatilities of nominal bond options than inflation targeting. The next section discusses this finding.

\section{Discussion}

\subsection{Inflation Uncertainty Does Not Matter}

According to (13), the bond price depends on inflation expectations. However, all monetary policy rules considered here set expected inflation to zero in every period, so there is no uncertainty about future inflation expectations. The volatility, $\operatorname{Var}_{t}\left(b_{t+1}\right)$, is therefore driven by uncertainty about future real interest rates only.

This feature of the model cannot be literally true. However, many articles on the Fisher effect (see, for instance, Mishkin (1990) and Söderlind (1998)) find that real interest rates are more volatile than inflation expectations - at least for maturities up to a year. This model feature may therefore be a reasonable approximation of reality.

\subsection{Inflation Targeting Destabilizes Real Interest Rates}

Since there is no uncertainty about future inflation expectations and consumption is proportional to output, the volatility in (15) can also be written

$$
\operatorname{Var}_{t}\left(b_{t+1}\right)=\operatorname{Var}_{t}\left[\mathrm{E}_{t+1}\left(y_{t+2}-y_{t+1}\right)\right],
$$

which is also the uncertainty about the future real interest rate.

Employment and output targeting give lower bond price volatility since those policies are good at stabilizing expected output growth, which inflation targeting is pretty bad at.

To understand this, we first note that monetary policy has only small effects beyond the quarter. This means that most of the differences in volatility across policy regimes are driven by differences in the uncertainty about next period's output. The reason for this result is as follows. Monetary policy can have a large impact on current output by surprising the labour market (effectively changing the real wage cost of firms). This could potentially give longlasting effects on output through capital accumulation (since current investments depend on current output). However, the capital stock is large compared to investment, so the dynamic effect is small. Based on this, we can focus on how current output is affected by a productivity shock and the monetary policy response. 


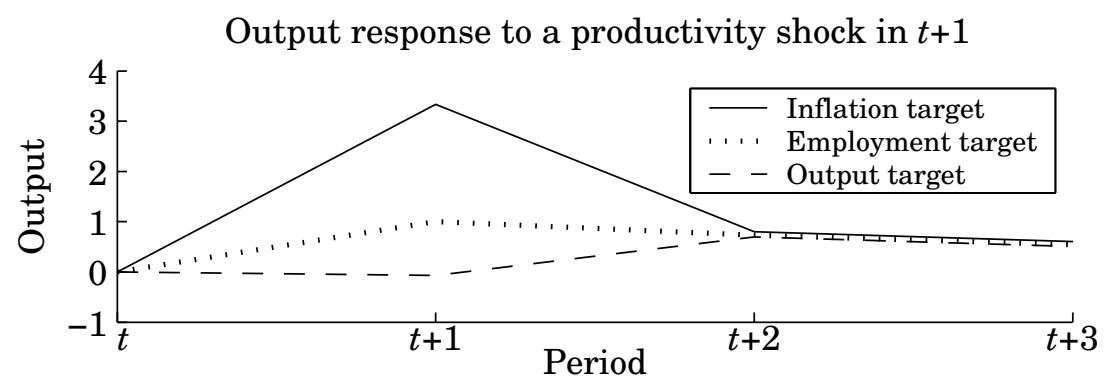

Figure 2: Response of output to a productivity shock. The figure uses $\rho=0.7, \alpha=0.3$, and $\delta=0.1$.

In an inflation targeting regime, a positive productivity shock in $t+1$ is met by an expansionary monetary policy (recall that $v=1 / \alpha>0$ ). As mentioned in Section 3 , the reason is that a positive shock increases output and therefore money demand. Unless the central bank increases the money supply, this will lead to a fall in prices. The side effect of expanding the money supply is, of course, that output is boosted further. This is illustrated in Figure 2, which shows the output response to a productivity shock in $t+1$.

In contrast, with employment targeting the central bank abstains from cushioning the productivity shock. This means that output is expected to be very similar in $t+1$ and $t+2$, since the productivity level is highly autocorrelated.

Finally, with output targeting the central bank tries to buffer the productivity shock completelyor even engineer a recession in order to bring down also future output (through lower capital accumulation). This could possibly lead to more volatility than inflation targeting-if the central bank would chose to generate a really large recession. It will not, however, since the effect on the capital stock (and future output) is small anyway.

To sum up, inflation targeting implies a pro-cyclical monetary policy. This stabilizes inflation, but destabilizes real interest rates-which are the main movers of nominal interest rates in the model.

The crucial features of this mechanism are that only monetary policy surprises have real effects, that those effects are immediate, and that capital accumulation plays only a small role. Neither is likely to be completely true, but they can be reasonable approximations if we interpret the periods as a few quarters or perhaps a year. Empirical research typically finds that unanticipated policy moves have much stronger effects than anticipated moves, that the real effects of monetary policy peak within a few quarters, and that capital accumulation is not very impor- 
tant for short-run business movements (although investments can be an important component of aggregate demand). These features are also shared by many theory-based models of monetary policy (see, for instance, Woodford (2002) for a summary).

\subsection{More Shocks}

In order to keep the analysis tractable, there is only one source of uncertainty in the model - the productivity shock. Some extensions can be made, however. For instance, a money demand shock (a shock to a stochastic weight on cash in the utility function) would be completely offset in all policy regimes here. As in standard models, such a shock moves prices and employment/output in the same direction, so there is no trade-off.

\subsection{Suggestions for Future Research}

I have a few suggestions for future work on the effect of monetary policy on derivatives pricing. First, it would be interesting to study the mapping from macro models of monetary policy to finance models of the yield curve. Second, it would also be interesting to extend the work in this paper by using a more detailed macro model with longer nominal stickiness (for instance, a Calvo model), higher risk aversion (lower intertemporal elasticity of substitution), and more inertia in aggregate demand. Third, the results in this paper could be tested by comparing bond option pricing in different monetary policy regimes (countries or periods). 


\section{A Details on the Optimization Problems}

\section{A.1 Derivation of (10)-(11)}

To see that $\operatorname{Var}\left(\mathrm{E}_{t-1} \pi_{t}\right)=0$, take first differences of (6)

$$
\pi_{t}=\left(m_{t}-m_{t-1}\right)-\left(y_{t}-y_{t-1}\right) .
$$

Since $\varepsilon_{t}$ is iid, it is clear from comparing (8) to (10) that $\mathrm{E}_{t-1} m_{t}-m_{t-1}=\mathrm{E}_{t-1} y_{t}-y_{t-1}$, so $\mathrm{E}_{t-1} \pi_{t}=0$.

From (7) and (10) we get (using $\left.h_{t}=m_{t}-\mathrm{E}_{t-1} m_{t}=v \varepsilon_{t}\right)$ that $\operatorname{Var}\left(h_{t}\right)=\operatorname{Var}\left(v \varepsilon_{t}\right)$, so

$$
\partial \operatorname{Var}\left(h_{t}\right) / \partial v=v 2 \sigma^{2} \text {. }
$$

From (17) the innovation in inflation equals the innovation in money supply ( $v \varepsilon_{t}$, see (10)) minus the innovation in output $\left((1-\alpha) h_{t}+\varepsilon_{t}\right.$, see (8)). From (7) we have $h_{t}=v \varepsilon_{t}$, so $\operatorname{Var}\left(\pi_{t}-\mathrm{E}_{t-1} \pi_{t}\right)=\operatorname{Var}\left(\alpha \nu \varepsilon_{t}-\varepsilon_{t}\right)=(\alpha \nu-1)^{2} \sigma^{2}$, which gives

$$
\partial \operatorname{Var}\left(\pi_{t}-\mathrm{E}_{t-1} \pi_{t}\right) / \partial v=\alpha(\alpha \nu-1) 2 \sigma^{2} .
$$

To get $v$ in (10), note that the first order condition for $\min \lambda \operatorname{Var}\left(h_{t}\right)+(1-\lambda) \operatorname{Var}\left(\pi_{t}-\mathrm{E}_{t-1} \pi_{t}\right)$ is (using (18) and (19)), $\lambda \nu+(1-\lambda) \alpha(\alpha \nu-1)=0$.

\section{A.2 Derivation of $v$ with Output Targeting}

If we let

$$
\tilde{a}=\rho+\delta-1, b=1-\delta+\alpha \delta, c=-(1-\alpha)(1-\delta),
$$

then using (7) and (10) in (8) allows us to write output on moving average form (after some straightforward calculations)

$$
y_{t}=\varepsilon_{t}[1+(1-\alpha) v]+\sum_{s=1}^{\infty} \varepsilon_{t-s} b^{s}\left[(\tilde{a} / b) \sum_{\tau=0}^{s-1}(\rho / b)^{\tau}+1+(c / b+1-\alpha) v\right] .
$$

The variance of output is therefore (since $\varepsilon_{t}$ is iid with variance $\sigma^{2}$ )

$$
\operatorname{Var}\left(y_{t}\right)=\sigma^{2}[1+(1-\alpha) v]^{2}+\sigma^{2} \sum_{s=1}^{\infty} b^{2 s}\left[(\tilde{a} / b) \sum_{\tau=0}^{s-1}(\rho / b)^{\tau}+1+(c / b+1-\alpha) v\right]^{2} .
$$

The derivative with respect to $v$ (divided by $2 \sigma^{2}$ ) is

$$
\begin{aligned}
\frac{\partial \operatorname{Var}\left(y_{t}\right)}{\partial v} \frac{1}{2 \sigma^{2}} & =[1+(1-\alpha) v](1-\alpha) \\
& +\sum_{s=1}^{\infty} b^{2 s}\left[(\tilde{a} / b) \sum_{\tau=0}^{s-1}(\rho / b)^{\tau}+1+(c / b+1-\alpha) v\right](c / b+1-\alpha) .
\end{aligned}
$$

By using Cauchy's product rule this can be simplified as

$$
\frac{\partial \operatorname{Var}\left(y_{t}\right)}{\partial v} \frac{1}{2 \sigma^{2}}=[1+(1-\alpha) v](1-\alpha)+\left[\frac{\tilde{a}}{b-b^{2} \rho}+1+(c / b+1-\alpha) v\right] \frac{b^{2}(c / b+1-\alpha)}{1-b^{2}} \text {. }
$$


Setting $\partial \operatorname{Var}\left(y_{t}\right) / \partial v=0$ and solving for $v$ gives

$v=-\left[1-\alpha+\frac{b^{2}}{1-b^{2}}(1-\alpha+c / b)\left(1+\frac{\tilde{a}}{b-b^{2} \rho}\right)\right] /\left[(1-\alpha)^{2}+\frac{b^{2}}{1-b^{2}}(1-\alpha+c / b)^{2}\right]$.

\section{References}

Bénassy, J.-P., 1995, "Money and Wage Contracts in an Optimizing Model of the Business Cycle," Journal of Monetary Economics, 35, 303-315.

Cassou, S. P., and K. J. Lansing, 1998, “Optimal Fiscal Policy, Public Capital, and the Productivity Slowdown," Journal of Economic Dynamics and Control, 22, 911-935.

Collard, F., 1999, "Spectral and Persistence Properties of Cyclical Growth," Journal of Economic Dynamics and Control, 23, 463-488.

Cooley, T. F., and G. D. Hansen, 1995, "Money and the Business Cycle," in Thomas F. Cooley (ed.), Frontiers of Business Cycle Research, Princeton University Press, Princeton, New Jersey.

Cooley, T. F., and E. C. Prescott, 1995, "Economic Growth and Business Cycles," in Thomas F. Cooley (ed.), Frontiers of Business Cycle Research, Princeton University Press, Princeton, New Jersey.

Hercowitz, Z., and M. Sampson, 1991, "Output, Growth, the Real Wage, and Employment Fluctuations," American Economic Review, 81, 1215-1237.

Huang, C.-F., and R. H. Litzenberger, 1988, Foundations for Financial Economics, Elsevier Science Publishing, New York.

Long, J. B., and C. I. Plosser, 1983, "Real Business Cycles," Journal of Political Economy, 91, 39-69.

Mishkin, F., 1990, “What Does the Term Structure Tell us about Future Inflation?," Journal of Monetary Economics, 25, 77-95.

Söderlind, P., 1998, “Nominal Interest Rates as Indicators of Inflation Expectations," Scandinavian Journal of Economics, 100, 457-472. 
Woodford, M., 2002, Interest and Prices: Foundations of a Theory of Monetary Policy, manuscript prepared for Princeton University Press. 